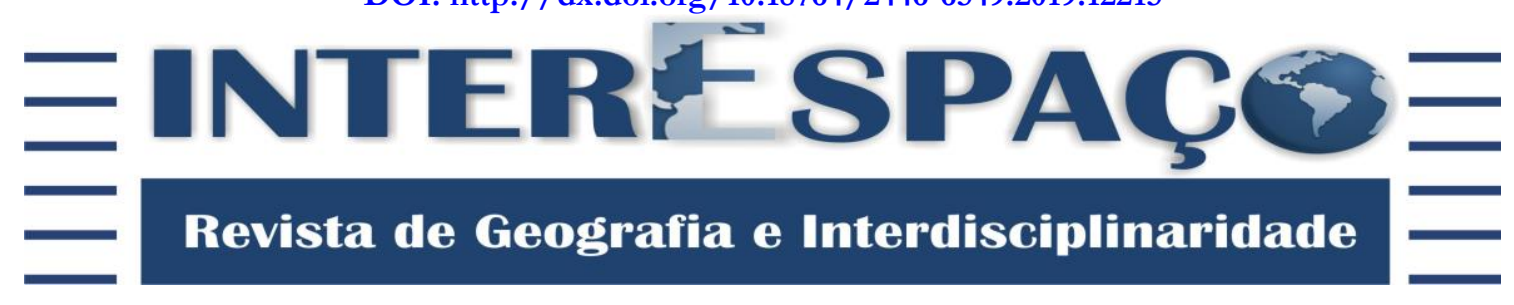

\title{
ANÁLISE DO USO E COBERTURA DA TERRA NA BACIA HIDROGRÁFICA DO RIO MOCAJUBA-PA
}

\author{
ANALYSIS OF LAND USE AND COVERAGE IN THE MOCAJUBA-PA RIVER \\ WATER BASIN
}

\section{ANÁLISIS DE USO DE LA TIERRA Y COBERTURA EN LA CUENCA DEL RÍO MOCAJUBA-PA}

\section{Juliane da Costa Cavalcante}

Mestra em Ciências Ambientais pela Universidade Federal do Pará - UFPA e Graduada em Engenharia Ambiental pela Universidade Estadual do Pará - UEPA. julianecosta63@gmail.com / http://orcid.org/0000-0002-8013-3764

Aline Maria Meiguins de Lima

Doutora em Desenvolvimento Sustentável do Trópico Úmido pela Universidade Federal do Pará UFPA. Docente do Programa de Pós-graduação em Ciências Ambientais na UFPA. alinemeiguins@gmail.com / http://orcid.org/0000-0002-0594-0187

Recebido para avaliação em 03/09/2019; Aprovado para publicação em 20/11/2019.

\section{RESUMO}

A bacia hidrográfica do Rio Mocajuba vem sofrendo alterações de suas características naturais devido à expansão de atividades antrópicas, colocando em risco áreas de manguezais que são protegidas por Unidades de Conservação. Dessa forma, o presente artigo objetiva quantificar as alterações do uso da terra na bacia nos anos de 1999 e 2018. Para a operacionalização da pesquisa foram utilizadas duas técnicas de classificação supervisionada (pixel a pixel e orientada a objeto) assim como visita em campo para validação da classificação. As classificações obtiveram um índice Kappa entre 0,73 e 0,92. A área da bacia, entre os anos de 1999 e 2018, obteve um aumento na classe composta por ocupações antrópicas de $48 \%$ na classificação orientada a objeto e $55 \%$ na classificação pixel a pixel. Por outro lado, áreas com formação florestal obtiveram uma diminuição de $33 \%$ na classificação orientada a objeto e $29 \%$ na classificação pixel a pixel.

Palavras-chave: Recursos Hídricos; Reservas Extrativistas; Manguezais; Sensoriamento Remoto.

\section{ABSTRACT}

The Mocajuba River watershed has been changing its natural characteristics due to the expansion of anthropic activities, putting at risk mangrove areas that are protected by Conservation Units. Thus, the present article aims to quantify land use changes in the basin in 1999 and 2018. For the operationalization of the research, two supervised classification techniques (pixel-based and objectoriented classification) as well as field visit were used for classification validation. The ratings obtained a Kappa index between 0.73 and 0.92. Between 1999 and 2018, the catchment area increased by $48 \%$ in the anthropic occupation class in the object-oriented classification and $55 \%$ in the pixel-based classification. On the other hand, areas with forest formation achieved a $33 \%$ decrease in object-oriented classification and 29\% in pixel-based classification.

Keywords: Water Resources; Extractive Reserves; Mangroves; Remote Sensing. 


\begin{abstract}
RESUMEN
La cuenca del río Mocajuba ha estado cambiando sus características naturales debido a la expansión de las actividades antrópicas, poniendo en riesgo las áreas de manglares que están protegidas por las Unidades de Conservación. Por lo tanto, el presente artículo tiene como objetivo cuantificar los cambios en el uso del suelo en la cuenca en 1999 y 2018. Para la operacionalización de la investigación, se utilizaron dos técnicas de clasificación supervisada (píxel por píxel y orientada a objetos), así como la visita de campo para la validación de clasificación. Las calificaciones obtuvieron un índice Kappa entre 0.73 y 0.92. Entre 1999 y 2018, el área de captación aumentó en un $48 \%$ en la clase de ocupación antrópica en la clasificación orientada a objetos y en un $55 \%$ en la clasificación píxel por píxel. Por otro lado, las áreas con formación forestal obtuvieron una disminución del $33 \%$ en la clasificación orientada a objetos y del $29 \%$ en la clasificación píxel por píxel.
\end{abstract}

Palabras clave: Recursos Hídricos; Reservas Extractivas; Manglares; Detección Remota.

\title{
INTRODUÇÃO
}

As últimas décadas têm ocasionado preocupação às organizações governamentais e sociedade em razão das mudanças ambientais na região Amazônica, impulsionadas pelo avanço de cultivos agrícolas, pastagens e expansão de áreas urbanas. Tornando-se um problema global à medida que as ocupações humanas se apropriam dos recursos naturais por meio de práticas ambientais não sustentáveis (SILVA; BACANI, 2017).

A expansão acelerada dessas ocupações sem planejamento ocasiona inúmeros processos prejudiciais aos ecossistemas naturais, como erosão, assoreamento de cursos d'água, infertilidade do solo, perda de biodiversidade e fragmentação florestal (SAMPAIO et al., 2018). Essas degradações acabam por acentuar a fragilidade natural do ambiente, rompendo o estado de "equilíbrio dinâmico" e acarretando o declínio da resiliência desses ecossistemas (SPINELLI et al., 2016; VALLE et al., 2016).

A bacia do Rio Mocajuba - PA, localizada entre os municípios de São João da Ponta, Curuçá e Terra Alta, vem sofrendo alterações de suas características naturais desde a década de 60 em razão da expansão agropecuária e urbana. Atualmente há predominância de vegetação secundária, confirmando o fato de uma área que foi densamente ocupada, além de áreas urbanas e agrícolas. Essas práticas antrópicas vêm colocando em risco as Unidades de Conservação que integram a bacia, possuindo usos e ocupações irregulares que vem se expandindo no entorno das zonas de amortecimento e no interior das Reservas Extrativistas - RESEX (TELES; PIMENTEL, 2015).

A zona costeira do Nordeste Paraense é composta por 15 unidades de conservação, sendo 13 reservas extrativistas (MMA, 2019). Essas unidades foram criadas com o objetivo de proteger grandes áreas de manguezais, que abrigam comunidades tradicionais que obtém dos mangues os recursos para a sua sobrevivência por meio da pesca artesanal, retirada de 
caranguejos e agricultura de subsistência. Sendo assim, a preservação dessas áreas é de suma importância na manutenção do equilíbrio ecológico e sustendo das populações costeiras, que sobrevivem dos bens e serviços ecossistêmicos provindos dos manguezais.

Diante disso, a análise temporal do uso e cobertura da terra na bacia do Rio Mocajuba é relevante por mostrar a expansão de atividades antrópicas, que provocam ameaças e pressionam as unidades de conservação presentes no local. Além se servir de subsídio para o planejamento e ordenamento territorial, frente à inexistência de plano de manejo dessas unidades.

Para Paz e Vieira (2018), em razão da expansão dessas atividades antrópicas, estudos voltados ao conhecimento dos usos e diferentes coberturas da terra representam informações significativas no fornecimento de subsídios ao monitoramento e planejamento ambiental. Nessa perspectiva se encontram os diferentes métodos de classificação de uso e cobertura da terra, que através de distintas abordagens buscam identificar informações de pixels e segmentos, classificando-os em categorias (VALE et al., 2018).

Deste modo, o objetivo do presente trabalho foi quantificar alterações do uso e cobertura da terra na Bacia do Rio Mocajuba-PA nos anos de 1999 e 2018, utilizando duas técnicas de classificação supervisionada: pixel a pixel e orientada a objeto (GEOBIA). Com o propósito de observar a expansão de atividades antrópicas que colocam em risco RESEX marinhas que fazem parte da bacia.

\section{MATERIAIS E MÉTODOS}

\section{Área de Estudo}

A área de estudo compreende a bacia hidrográfica do rio Mocajuba, que faz parte dos municípios de São João da Ponta, Curuçá e Terra Alta, com localização no Nordeste do Estado do Pará. Em seus limites estão contidas partes de três Reservas Extrativistas Marinhas, a RESEX de São João da Ponta, Mãe Grande de Curuçá e Mocapajuba. A bacia possui uma área de aproximadamente $406 \mathrm{~km}^{2}$ e sua delimitação foi obtida por meio dos dados do SRTM (ID: SRTM1S01W048V3) disponível no site do United States Geological Survey - USGS (2018), através da ferramenta ArcHydro do Software ArcMap 10.4. 
|Juliane da Costa Cavalcante | Aline Maria Meiguins de Lima |

Figura 01 - Localização da Bacia Hidrográfica do Rio Mocajuba.

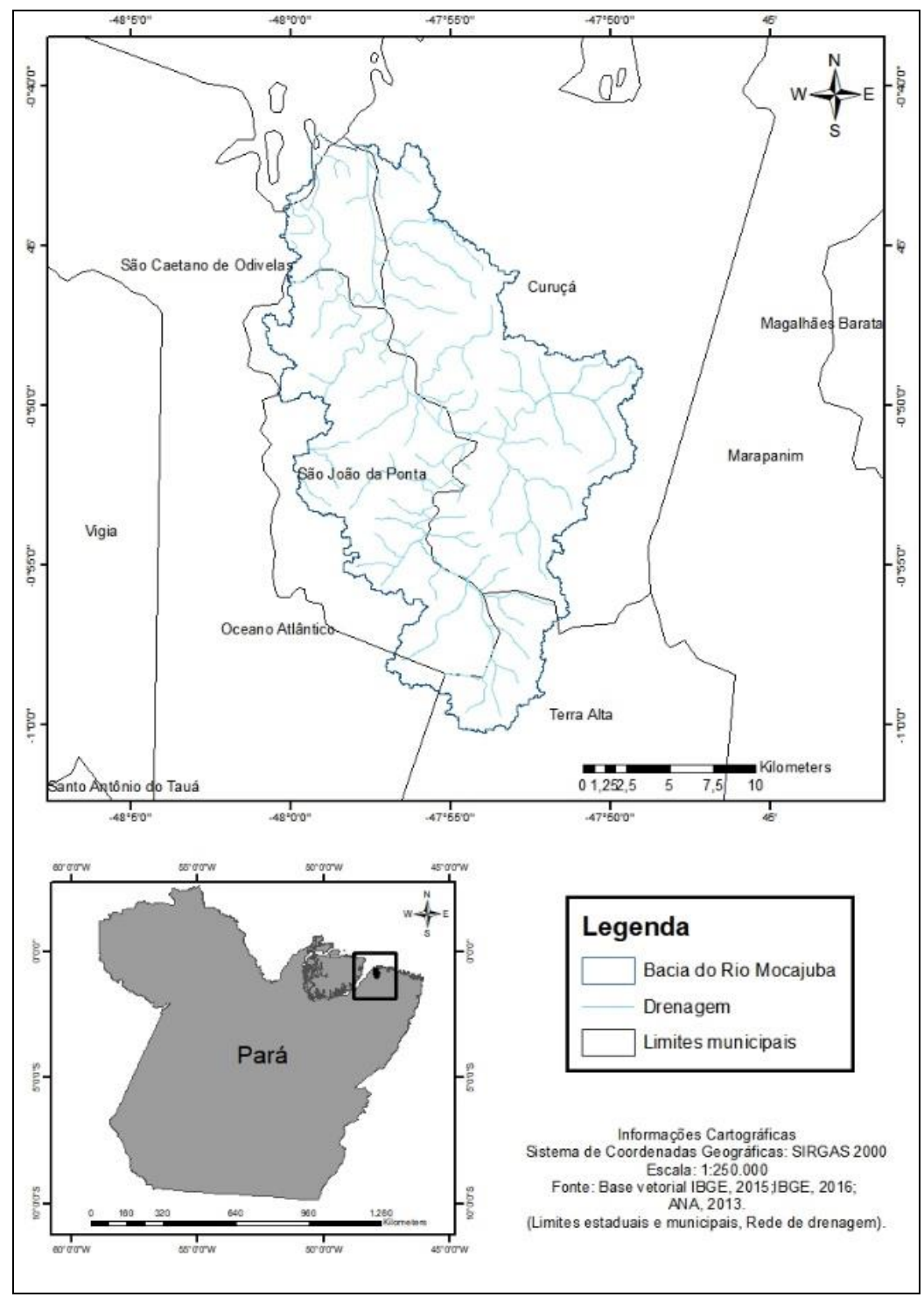

\section{Classificação supervisionada "pixel a pixel"}

- Plataforma de processamento e dados utilizados

A plataforma da Google Earth Engine (GEE), criada pela empresa Google, combina e disponibiliza múltiplas imagens de satélite e dados geoespaciais, podendo estes ser processados na nuvem da própria plataforma.

A referida plataforma traz as capacidades computacionais da Google para lidar com uma variedade de questões sociais de alto impacto, incluindo desmatamento, seca, desastres, doenças, segurança alimentar, gerenciamento de água, monitoramento climático e proteção ambiental. Seu catálogo disponibiliza publicamente um grande repositório de dados, incluindo observações de uma variedade de sistemas de imagens aéreas e de satélite, variáveis ambientais, previsões climáticas, cobertura territorial, dados topográficos e 
socioambientais. Todos esses dados são pré-processados e disponibilizados prontos para uso (GORELICK et al., 2016).

Alguns dados disponíveis na plataforma são de: queimadas, temperatura de superfície, modelos digitais de elevação, índices de vegetação, assim como imagens da coleção Landsat, Sentinel e do sensor MODIS. Dados estes, que podem ser aplicados a uma variedade de disciplinas, como mudanças de florestas, rendimento de culturas, mapeamento urbano e mudanças de uso da terra. Para o mapeamento do uso do solo na Bacia do Rio Mocajuba foram utilizadas imagens da coleção do Landsat 7 e 8, dos anos de 1999 e 2018, respectivamente.

O Satélite Landsat 7 foi lançado na Califórnia em 15 de abril de 1999, carregando o sensor Enhanced Thematic Mapper (ETM+), uma versão melhorada dos instrumentos Thematic Mapper que estavam a bordo dos produtos Landsat 4 e 5. Possui oito bandas espectrais, onde se inclui uma pancromática e térmica. Atualmente se encontra ativo, mas com restrições de uso, pois desde junho de 2003 o sensor adquiriu e entregou dados com falhas do SLC (Scan Line Corrector) (USGS, 2018).

O Satélite Landsat 8 foi lançado, também na Califórnia, em 11 de fevereiro de 2013, transportando os sensores Operational Land Imager (OLI) e o Thermal Infrared Sensor (TIRS). O primeiro possuindo nove bandas, onde se inclui a cirrus e pancromática, e a segunda incluindo duas bandas termais de 100 m (USGS, 2018). As imagens utilizadas no estudo são da coleção do Landsat 7 e 8, nível 1, Calibrated Top of Atmosphere (TOA LANDSAT/LC08/C01/T1_RT_TOA e LANDSAT/LE07/C01/T1_RT_TOA), disponíveis na plataforma do GEE.

- Classificação e classes de amostragem

Foi utilizado o classificador Random Forest, disponível na plataforma do GEE, onde seu treinamento é baseado no agrupamento de vários classificadores tipo árvore (bootstrap), criando assim uma combinação de árvores de decisão (bagging ou bootstrap aggregating). Estes se combinam para a obtenção de uma predição com maior acurácia (GISLASON et al., 2005).

Primeiramente, por meio script na plataforma do GEE, foi aplicado um filtro para remoção de pixels com nuvens nas imagens capturadas entre 01/01/1999 e 31/12/1999, referente ao Landsat 7, assim como 01/01/2018 e 31/12/2018, referente ao Landsat 8. O script de remoção de nuvens utiliza a banda de Quality Assessment (QA) e um redutor mediano do GEE. Ao realizar isso a ferramenta recusa pixels muito brilhantes ou escuros (nuvens e sombras) e por meio de uma mediana, das imagens do ano de 1999 e 2018, gera 
uma única imagem sem nuvens para os respectivos anos (DINIZ et al., 2019; ROSA, 2018). A finalidade dessa metodologia e gerar uma imagem final livre de nuvens e com pixels "limpos", levando em consideração todas as imagens do ano de 1999 e 2018, respectivamente. A Figura 02 esquematiza as etapas metodológicas aplicadas.

Figura 02 - Fluxograma metodológico "pixel a pixel".

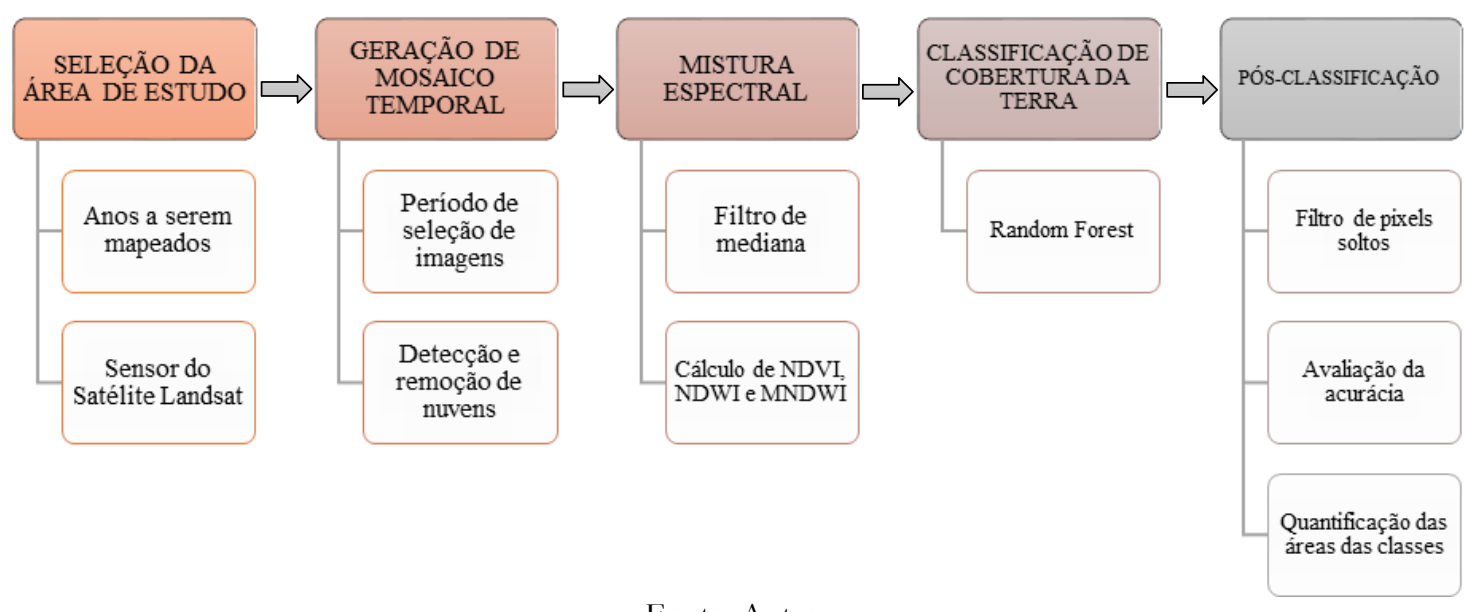

Fonte: Autor.

A partir das imagens selecionadas foram realizados os cálculos dos seguintes índices:

- Índice de Vegetação de Diferença Normalizada (NDVI) (eq. 1) utiliza a banda do vermelho (RED), canal com forte absorção de clorofila e do Infravermelho Próximo (NIR), canal com alta reflectância das copas das plantas. Nesse caso, as porções absorvidas do vermelho e refletidas do infravermelho variam de acordo com as condições da vegetação. Quanto mais verde, densa e sadia uma planta maior é a absorção do vermelho e maior a reflectância do infravermelho (BARBOSA et al., 2017).

$\mathrm{NDVI}=\frac{\text { NIR }-\mathrm{RED}}{\mathrm{NIR}+\mathrm{RED}}$

- Índice de Umidade de Diferença Normalizada (NDMI ou NDWI) (eq. 2) é derivado dos canais do infravermelho próximo (NIR) e infravermelho médio (SWIR). Sendo o infravermelho médio mais sensível à quantidade de água presente na vegetação e solo, então mais absorvido pela umidade das folhas e cobertura do dossel, tendo potencial para mapeamento de retirada da cobertura florestal (TEIXEIRA et al., 2019).

$\mathrm{NDMI}=\frac{\mathrm{NIR}-\mathrm{SWIR}}{\mathrm{NIR}+\mathrm{SWIR}}$

- Índice de Água de Diferença Normalizada Modificada (MNDWI) (eq. 3) utiliza bandas do verde (Green) e infravermelho médio (SWIR), em que a banda do verde e infravermelho 
médio possui maior absorção pela umidade da vegetação, solo úmido e recursos hídricos. Sendo que o oposto ocorre para áreas com solo exposto. A utilização do SWIR ao invés do NIR é uma maneira de maximizar ainda mais a diferença entre as bandas (PEREIRA et al., 2016).

MNDWI $=\frac{\text { Green }-S W I R}{G r e e n+S W I R}$

A partir da imagem final, gerada pela mediana, se fez a amostragem de cada classe a ser classificada: Água, manguezal, formação florestal e não floresta. As classes mapeadas são descritas no Quadro 01.

Quadro 01 - Caracterização das classes de cobertura da terra mapeadas

\begin{tabular}{|c|l|}
\hline Classes & \multicolumn{1}{|c|}{ Descrição } \\
\hline Água & $\begin{array}{l}\text { Incluindo todas as classes de água, tais como: oceano, rios, lagos } \\
\text { naturais e artificiais, entre outros. }\end{array}$ \\
\hline Manguezal & $\begin{array}{l}\text { Baseado no manual técnico de vegetação do IBGE (2012): Vegetação } \\
\text { com influência fluviomarinha (manguezal e apicum). }\end{array}$ \\
\hline Formação florestal & $\begin{array}{l}\text { Baseado no manual técnico de vegetação do IBGE (2012): Vegetação } \\
\text { ombrófila densa pioneira e secundária. Além de áreas em estado inicial } \\
\text { de regeneração. }\end{array}$ \\
\hline Não floresta & $\begin{array}{l}\text { Cobertura de terra com usos antrópicos variados, tais como: áreas } \\
\text { urbanas, pastagem, agricultura, rodovias e solo exposto. }\end{array}$ \\
\hline
\end{tabular}
Organização: Autoras.

\section{Classificação orientada a objeto}

As imagens de satélite selecionadas para a referida classificação foram do sensor Landsat Enhanced Thematic Mapper Plus (ETM +) a bordo do satélite Landsat 7, órbita 223, ponto 61, imageada em 13/07/1999, com $2 \%$ de nuvem e ID: LE07_L1TP_223061_19990713_20170218_01_T1. E da imagem do sensor Operational Land Imager (OLI) e Thermal Infrared Sensor (TIRS) a bordo do satélite Landsat 8, órbita 223, ponto 61, imageada em 07/06/2018, com 1,58\% de nuvem e ID: LC08_L1TP_223061_20180607_20180615_01_T1, através do sítio da United States Geological Survey - USGS (USGS, 2018). O período climático do imageamento de ambas as imagens foi o início do verão amazônico (inverno no hemisfério Sul).

Utilizou-se como critério para a escolha das imagens aquelas com menor percentual de nuvens, visto que na metodologia de Classificação Orientada Objeto não é possível aplicar filtro de nuvens como na metodologia do tópico anterior na plataforma do GEE.

Ambas as imagens Landsat passaram por pré-processamento no Software PCI Geomatics 2015. Estas foram reprojetadas para o hemisfério Sul, aplicada à correção atmosférica e recortadas, utilizando como máscara o limite da bacia hidrográfica. 
Posteriormente foi realizada a classificação orientada a objeto (GEOBIA - Geographic Object-Based Image Analysis) no Software eCognition Developer 9, com a segmentação (algoritmo multiresolution segmentation) testada para diferentes tamanhos de segmentos e escolhido o que obteve melhor resultado.

Os parâmetros de segmentação utilizados em ambas as imagens Landsat foram: escala (2), cor $(0,1)$, forma $(0,4)$, suavidade $(0,2)$ e compacidade $(0,3)$. A escala determina o tamanho da segmentação, em que um valor alto gera objetos maiores (menos segmentos) e um valor baixo gera objetos menores (mais segmentos). Cor e forma são consideradas juntamente, onde uma maior ponderação na forma dos segmentos implica em menor ponderação na cor (características espectrais). Da mesma forma funciona suavidade e compacidade, em que um baixo valor de compacidade (agrupamento/compactação de pixels em um segmento) implica em maior valor na suavidade (regularidade de contorno do objeto, ou seja, suavidade de bordas) (PIAZZA; VIBRANS, 2014).

Para a classificação foram utilizados além das bandas os índices NDVI, NDWI e MNDWI. Assim como o índice AWEI (Índice automático de extração de água), que leva em consideração as bandas do verde - Green; infravermelho médio - SWIR; infravermelho próximo - NIR, de acordo com a seguinte fórmula (eq. 4):

$A W E I=4 \times($ Green $-S W I R 2)-(0.25 \times N I R+2.75 \times S W I R 1)$

O índice automático de extração de água (AWEI) busca maximizar a diferença entre áreas de água, oferecendo um valor limite estável para diferenciar água de outras coberturas da terra (KWANG et al., 2017). Optou-se por utilizar o índice AWEI na classificação GEOBIA para facilitar o processo de segmentação de todo o corpo hídrico, incluindo afluentes menores. Já na classificação pixel a pixel, na plataforma do GEE, decidiu-se por não utilizar o AWEI, visto que este aumentou os ruídos da classificação de cada pixel.

A Figura 03 simplifica as principais etapas do processo de classificação GEOBIA. Após a classificação realizou-se uma reclassificação por meio de edição manual de dados, corrigindo falhas de mapeamento das classes mapeadas. 
|Juliane da Costa Cavalcante | Aline Maria Meiguins de Lima |

Figura 03 - Fluxograma metodológico GEOBIA.

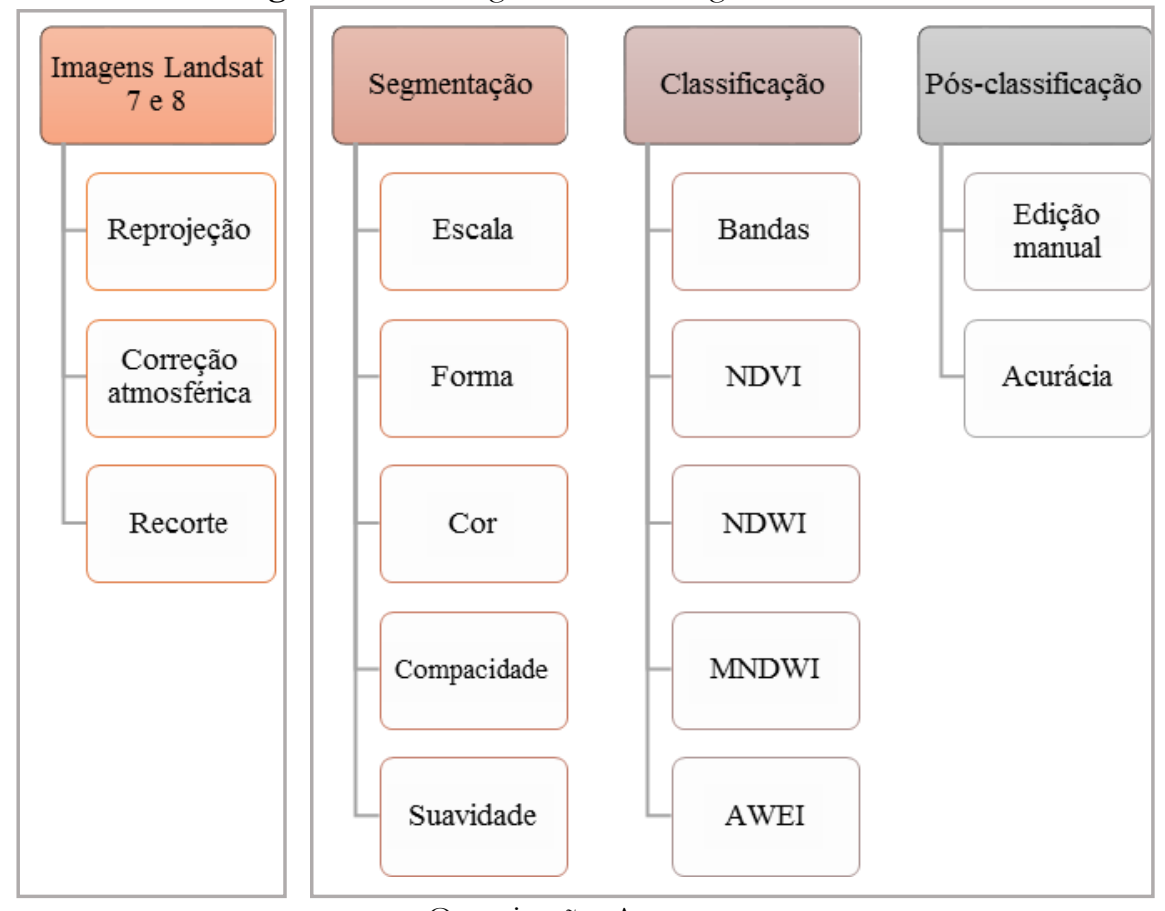

Organização: Autoras.

\section{Validação do Mapeamento}

- Visita de Campo

Foi realizada uma campanha de campo em junho de 2019. Para a amostragem escolheu-se pontos que obtiveram diferenças de mapeamento entre as duas metodologias de classificação utilizadas no estudo. A quantidade mínima de pontos utilizada para validação foi definida conforme Jensen (1996) e utilizada por Fernandes et al. (2012). Onde P é o percentual de exatidão esperado; $Q=1$ - P; E é o erro admissível (eq. 5):

$N=\frac{4 P \times Q}{E^{2}}$

Para obter um percentual de exatidão de $95 \%$ e erro admissível de 5\%, o número mínimo de pontos utilizados deveria ser igual a 76. Optou-se por utilizar mias que isso, 200. Destes, apenas 84 foram amostrados durante as campanhas de campo e, para a validação dos demais pontos foram utilizadas imagens RapidEye (resolução de 5 metros) e imagens disponíveis no Google Earth Pro, como fontes de validação.

\section{- Cálculo da Acurácia}

A exatidão de um mapa indica a proximidade da classificação realizada com a classe real. Então é necessário o conhecimento do quão correto são os dados provenientes dos distintos métodos de classificação. Para isso se utilizou do Coeficiente Kappa e Exatidão 
Global para se calcular a acurácia das classificações realizadas a partir da matriz de confusão. Onde K e uma estimativa do coeficiente Kappa; $\sum_{i=1}^{c} x i i$ é a soma dos elementos da matriz na diagonal principal; [ $c$ ] é o número de linhas; [ xii ] é o valor na linha [i] e coluna [i]; [ $x i+]$ é a soma da linha $[i]$ e $[x+i]$ é a soma da coluna $[i] \mathrm{da}$ matriz de confusão; e [ $n$ ] é o número total de amostras (VALE et al., 2018). (eq. 6)

Kappa $=\frac{n \sum_{i=1}^{c} x_{i i}-\sum_{i=1}^{e} x_{i+} x_{+i}}{n^{2}-\sum_{i=1}^{c} x_{i+} x_{+i}}$

A qualidade da classificação de acordo com coeficiente Kappa pode ser analisado de acordo com a Tabela 01.

Tabela 01 - Qualidade associada a valores do Coefici
\begin{tabular}{l|l}
\hline Índice Kappa & Qualidade \\
\hline 0 & Péssimo \\
\hline $0,01-0,2$ & Ruim \\
\hline $0,21-0,4$ & Razoável \\
\hline $0,41-0,6$ & Boa \\
\hline $0,61-0,8$ & Muito boa \\
\hline $0,81-1$ & Excelente \\
\hline Fonte: VALE et al. (2018).
\end{tabular}

A Exatidão Global é uma das medidas mais simples de verificação de acurácia, em que relaciona-se os elementos da diagonal com o total de pontos amostrados. Onde $A$ é o número de pontos amostrais com acerto e $n$ o número de pontos amostrados (VALE et al., 2018). (eq. 7)

Exatidão Global $=\frac{A}{n} \times 100$

\section{RESULTADOS E DISCUSSÕES}

No relativo à comparação dos produtos gerados para a classificação GEOBIA, e para o Random Forest, a partir dos pontos de verdade terrestre e do uso de imagens de alta resolução, foi possível elaborar a matriz de confusão com resultados do coeficiente Kappa qualificados como "excelente" para a classificação Random Forest de 1999 e "muito boa" para as demais classificações. Todas as classificações obtiveram exatidão global acima de $80 \%$, de acordo com a Tabela 02 . 
|Análise do uso e cobertura da terra na bacia hidrográfica do rio Mocajuba-PA|

|Juliane da Costa Cavalcante | Aline Maria Meiguins de Lima |

Tabela 02 - Valores obtidos pelo Coeficiente Kappa e Exatidão Global

\begin{tabular}{c|c|c|c|c}
\hline \multirow{2}{*}{ Classes } & \multicolumn{2}{|c}{1999} & \multicolumn{2}{c}{2018} \\
\cline { 2 - 5 } & GEOBIA & Random Forest & GEOBIA & Random Forest \\
\hline Exatidão Global (\%) & 85,5 & 95 & 81 & 86 \\
\hline Coeficiente Kappa & 0,79 & 0,92 & 0,73 & 0,80 \\
\hline
\end{tabular}

Organização: Autoras.

Os resultados de exatidão da classificação GEOBIA mostraram-se parecidos com o realizado por Silva e Bacani (2017), na classificação de uso da terra da bacia do Rio da Prata (MS), obtendo Coeficiente Kappa próximo a 0,8 e Exatidão Global entre 80\% e 90\%.

Este tipo de classificação, mesmo sendo voltada para imagens de alta resolução, pode ser aplicada em imagens de média resolução combinando uma boa segmentação com matemática de bandas espectrais, como os índices de vegetação e água. Ampliando o grau de informação dos segmentos, como forma de aumentar a diferenciação de diferentes regiões.

Assim como a classificação GEOBIA, adicionar índices espectrais baseados em cálculos entre bandas pode aumentar a acurácia no classificador Random Forest. Isso foi observado por Rosa (2018) em um estudo no mapeamento de ocupações urbanas em São Paulo, onde sua classificação obteve um aumento do coeficiente Kappa de 0,74 para 0,77 e exatidão global $77 \%$ para $79 \%$ por meio do uso desses índices. Isso ocorre pelo incremento de novas informações nas árvores de decisão.

A classificação "pixel a pixel", do classificador Random Forest, obteve um Coeficiente Kappa e Exatidão Global mais elevados em comparação com a classificação GEOBIA. Esse tipo de classificação utiliza somente informações de pixels selecionados no processo de amostragem, deixando de lado outras características como forma e cor, que são levados em consideração na classificação GEOBIA. Como resultado gera uma classificação com pixels isolados, necessitando de uma edição pós-classificação (Tabela 03).

Tabela 03 - Exatidão das classes individuais das distintas classificações

\begin{tabular}{c|c|c|c|c}
\hline \multirow{2}{*}{ Classes } & \multicolumn{4}{|c}{ GEOBIA } \\
\cline { 2 - 5 } & \multicolumn{4}{|c}{1999} \\
\cline { 2 - 5 } & $\begin{array}{c}\text { Exatidão } \\
\text { Produtor }\end{array}$ & $\begin{array}{c}\text { Erros de } \\
\text { omissão }\end{array}$ & Exatidão Usuário & $\begin{array}{c}\text { Erros de } \\
\text { comissão }\end{array}$ \\
\hline Água & $89,19 \%$ & $10,81 \%$ & $89,18 \%$ & $10,81 \%$ \\
\hline Manguezal & $78,12 \%$ & $21,87 \%$ & $83,33 \%$ & $16,66 \%$ \\
\hline Não floresta & $79,62 \%$ & $20,37 \%$ & $82,69 \%$ & $17,30 \%$ \\
\hline Formação florestal & $90,90 \%$ & $9,09 \%$ & $86,41 \%$ & $13,58 \%$ \\
\hline
\end{tabular}


|Análise do uso e cobertura da terra na bacia hidrográfica do rio Mocajuba-PA|

|Juliane da Costa Cavalcante | Aline Maria Meiguins de Lima |

\begin{tabular}{|c|c|c|c|c|}
\hline \multirow[b]{2}{*}{ Classes } & \multicolumn{4}{|c|}{2018} \\
\hline & $\begin{array}{l}\text { Exatidão } \\
\text { Produtor }\end{array}$ & $\begin{array}{l}\text { Erros de } \\
\text { omissão }\end{array}$ & Exatidão Usuário & $\begin{array}{l}\text { Erros de } \\
\text { comissão }\end{array}$ \\
\hline Água & $88,88 \%$ & $11,11 \%$ & $91,42 \%$ & $8,57 \%$ \\
\hline Manguezal & $88,23 \%$ & $11,76 \%$ & $83,33 \%$ & $16,66 \%$ \\
\hline Não floresta & $73,75 \%$ & $26,25 \%$ & $88,05 \%$ & $11,94 \%$ \\
\hline Formação florestal & $82,00 \%$ & $18,00 \%$ & $66,12 \%$ & $33,87 \%$ \\
\hline \multirow{3}{*}{ Classes } & \multicolumn{4}{|c|}{ RANDOM FOREST } \\
\hline & \multicolumn{4}{|c|}{1999} \\
\hline & $\begin{array}{l}\text { Exatidão } \\
\text { Produtor }\end{array}$ & $\begin{array}{l}\text { Erros de } \\
\text { omissão }\end{array}$ & Exatidão Usuário & $\begin{array}{l}\text { Erros de } \\
\text { comissão }\end{array}$ \\
\hline Água & $97,29 \%$ & $2,7 \%$ & $97,29 \%$ & $2,7 \%$ \\
\hline Manguezal & $96,66 \%$ & $3,33 \%$ & $96,66 \%$ & $3,33 \%$ \\
\hline Não floresta & $97,82 \%$ & $2,17 \%$ & $86,53 \%$ & $13,46 \%$ \\
\hline Formação florestal & $91,95 \%$ & $8,04 \%$ & $98,76 \%$ & $1,23 \%$ \\
\hline \multirow[b]{2}{*}{ Classes } & \multicolumn{4}{|c|}{2018} \\
\hline & $\begin{array}{l}\text { Exatidão } \\
\text { Produtor }\end{array}$ & $\begin{array}{l}\text { Erros de } \\
\text { omissão }\end{array}$ & Exatidão Usuário & $\begin{array}{l}\text { Erros de } \\
\text { comissão }\end{array}$ \\
\hline Água & $92,10 \%$ & $7,89 \%$ & $100 \%$ & $0 \%$ \\
\hline Manguezal & $93,54 \%$ & $6,45 \%$ & $80,55 \%$ & $19,44 \%$ \\
\hline Não floresta & $78,48 \%$ & $21,51 \%$ & $92,53 \%$ & $7,46 \%$ \\
\hline Formação florestal & $88,46 \%$ & $11,53 \%$ & $74,19 \%$ & $25,80 \%$ \\
\hline
\end{tabular}

Organização: Autoras.

Por outro lado, a classificação GEOBIA obtém informações de um conjunto de pixels (regiões de pixels) com características homogêneas, onde pixels com características similares se tornam uma única região. É possível ocorrer que pixels de distintas classes se enquadrem no mesmo segmento, havendo a omissão e inclusão de pixels em uma determinada classe. Para Sousa et al. (2015) essa é uma desvantagem dessa técnica, onde há a associação de pixels de borda às regiões vizinhas. Isso pode ser observado por meio dos erros de omissão e comissão.

A acurácia do produtor está associada aos erros de exclusão, ou seja, pixels que deixaram de ser mapeados. A acurácia do usuário está associada ao erro de omissão, ou seja, pixels classificados incorretamente. De acordo com a Tabela 03 no classificador Random Forest foram observados erros de comissão e omissão menores que o GEOBIA, o que explica as diferenças entre as áreas por classe entre as distintas metodologias (Tabela 04 e 05). 
|Análise do uso e cobertura da terra na bacia hidrográfica do rio Mocajuba-PA|

|Juliane da Costa Cavalcante | Aline Maria Meiguins de Lima |

Tabela 04 - Matriz de Transição de áreas em $\mathrm{km}^{2}$ entre os agrupamentos de classes da área de estudo, nos

\begin{tabular}{|c|c|c|c|c|c|c|}
\hline $\begin{array}{l}\text { Classes } \\
\left(\mathrm{km}^{2}\right)\end{array}$ & Água & Manguezal & $\begin{array}{c}\text { Formação } \\
\text { florestal }\end{array}$ & $\begin{array}{c}\text { Não } \\
\text { floresta }\end{array}$ & Total 1999 & Perda \\
\hline Água & 21,39 & 1,58 & 0,016 & 0,048 & 23,03 & 1,64 \\
\hline Manguezal & 1,70 & 56,80 & 1,28 & 0,19 & 59,97 & 3,17 \\
\hline $\begin{array}{c}\text { Formação } \\
\text { florestal }\end{array}$ & 0,20 & 2,12 & 138,60 & 98,2 & 239,12 & 100,52 \\
\hline Não floresta & 0,08 & 0,07 & 18,24 & 66,16 & 84,55 & 18,39 \\
\hline $\begin{array}{l}\text { Total } \\
2018\end{array}$ & 23,37 & 60,57 & 158,14 & 164,59 & 406,67 & \\
\hline Ganho & 1,98 & 3,77 & 19,54 & 98,43 & & \\
\hline
\end{tabular}

Tabela 05 - Matriz de Transição de áreas em $\mathrm{km}^{2}$ entre os agrupamentos de classes da área de estudo, nos

\begin{tabular}{c|c|c|c|c|c|c}
\multirow{2}{*}{$\begin{array}{c}\text { Classes } \\
\left(\mathrm{km}^{2}\right)\end{array}$} & Água & Manguezal & $\begin{array}{c}\text { Formação } \\
\text { florestal }\end{array}$ & $\begin{array}{c}\text { Não } \\
\text { floresta }\end{array}$ & $\begin{array}{c}\text { Total } \\
\mathbf{1 9 9 9}\end{array}$ & Perda \\
\hline Água & 20,94 & 0,55 & 0,062 & 0,0026 & $\mathbf{2 1 , 5 5}$ & 0,61 \\
\hline Manguezal & 2,15 & 57,19 & 0,607 & 0,0259 & $\mathbf{5 9 , 9 7}$ & 2,78 \\
\hline $\begin{array}{c}\text { Formação } \\
\text { florestal }\end{array}$ & 0,047 & 2,11 & 170,69 & 92,18 & $\mathbf{2 6 5 , 0 2}$ & 94,33 \\
\hline Não floresta & 0,018 & 0,107 & 15,76 & 44,25 & $\mathbf{6 0 , 1 3}$ & 15,88 \\
\hline Total & $\mathbf{2 3 , 1 5}$ & $\mathbf{5 9 , 9 5}$ & $\mathbf{1 8 7 , \mathbf { 1 1 }}$ & $\mathbf{1 3 6 , 4 5}$ & $\mathbf{4 0 6 , 6 7}$ & \\
\hline $\mathbf{2 0 1 8}$ & 2,21 & 2,76 & 16,42 & 92,2 & &
\end{tabular}

As classes de água e manguezal obtiveram pouca diferença entre as metodologias de classificação. Por outro lado, as classes com maiores diferenças em área foram "formação florestal" e "não floresta", como apresentado nas Tabelas 04 e $05 . \mathrm{Na}$ classificação GEOBIA as áreas de "formação florestal" foram subestimadas e "não florestas" superestimadas, ou seja, devido aos altos erros de omissão em "formação florestal" e altos erros de comissão em "não floresta". O oposto ocorreu com o classificador Random Forest, devido aos erros de comissão e omissão menores (Figuras 04 e 05). 
|Análise do uso e cobertura da terra na bacia hidrográfica do rio Mocajuba-PA|

|Juliane da Costa Cavalcante | Aline Maria Meiguins de Lima |

Figura 04 - Mapa de uso e cobertura da terra da bacia hidrográfica do Rio Mocajuba de 1999 e 2018,
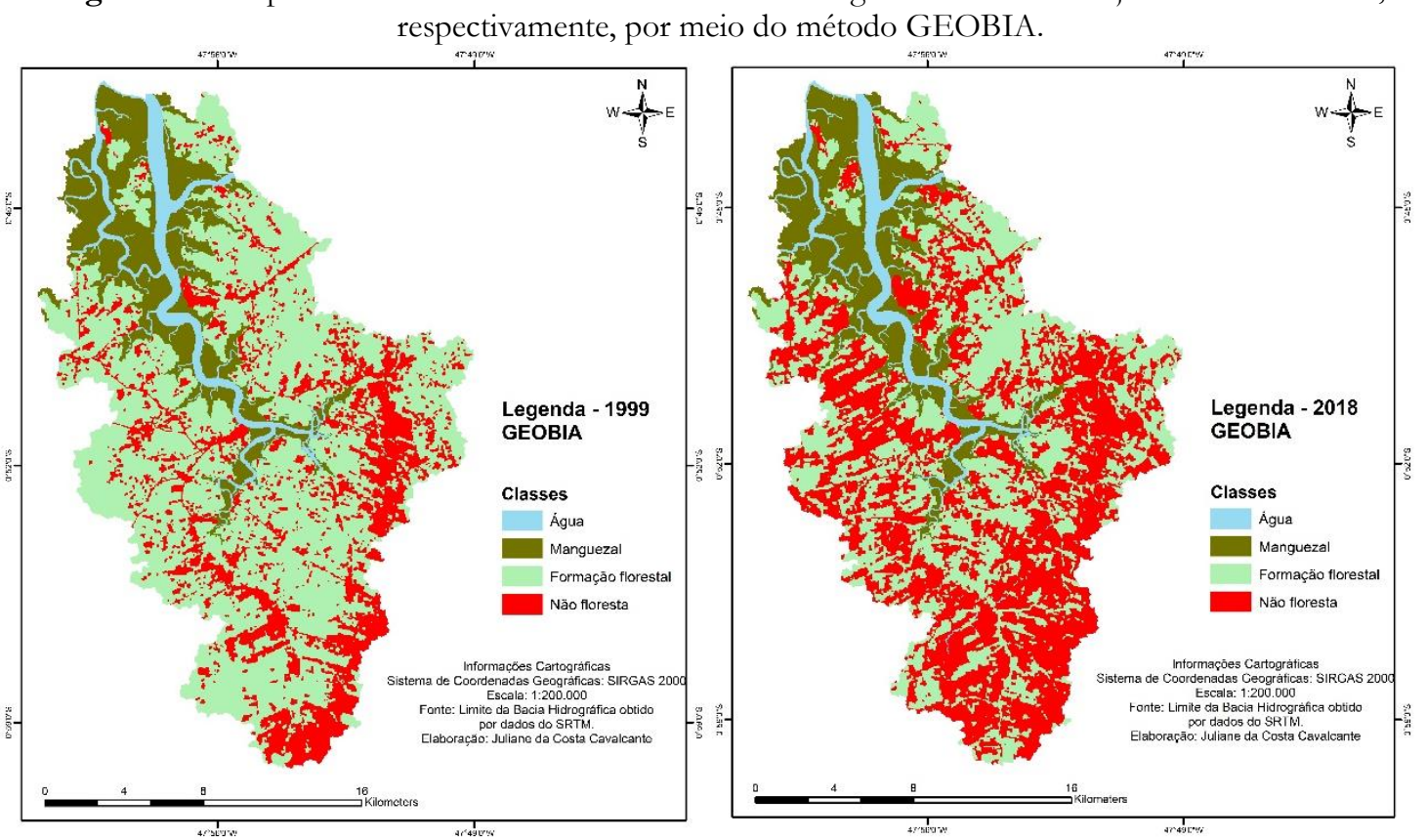

Figura 05 - Mapa de uso e cobertura da terra da bacia hidrográfica do Rio Mocajuba de 1999 e 2018, respectivamente, por meio do classificador Random Forest.
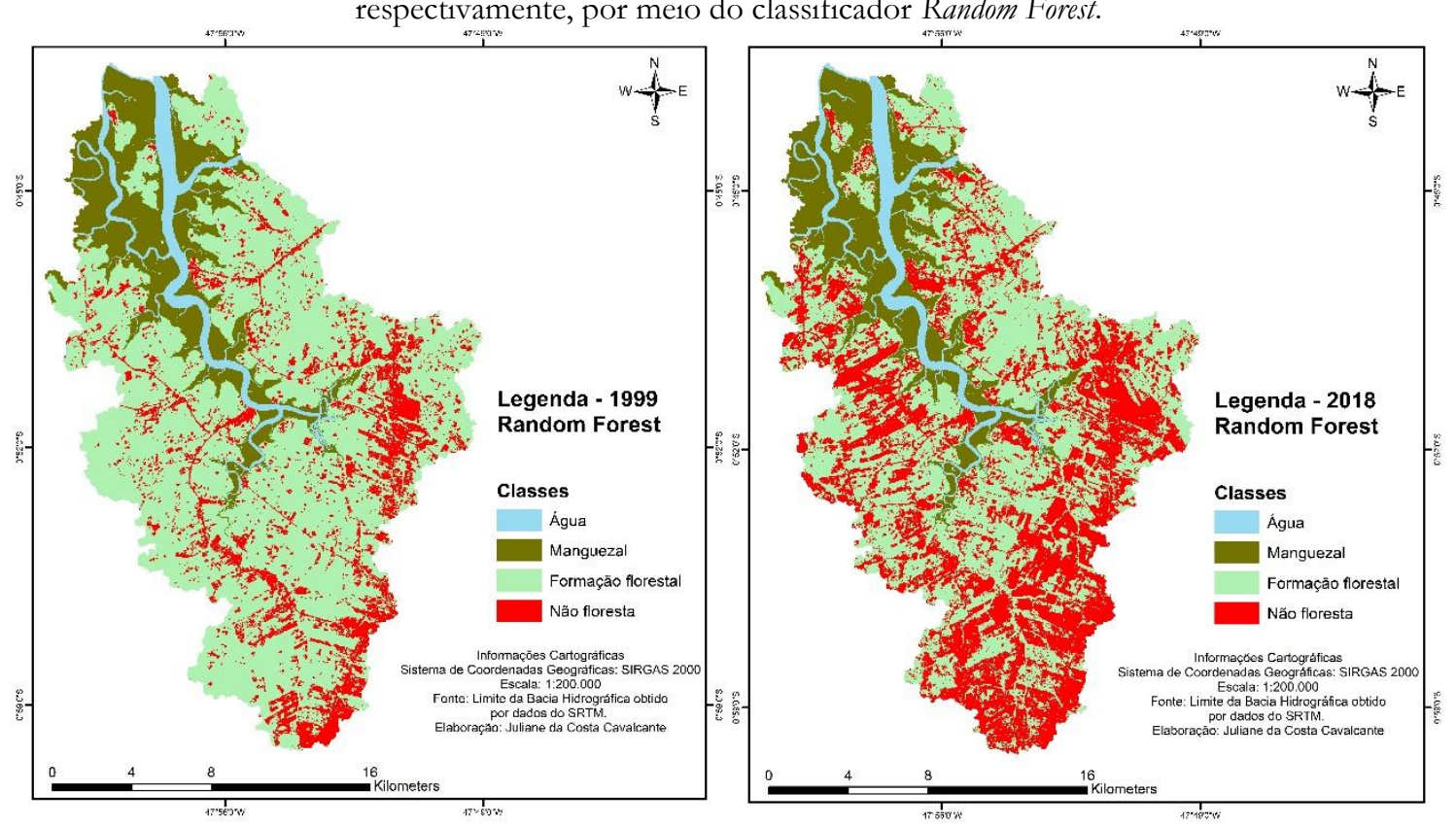

Ambos os métodos apresentaram Exatidão Global e Coeficiente Kappa “Altos", considerados como boas classificações de uso e cobertura da terra. Podendo compor estudos do processo de ocupação da bacia do Rio Mocajuba e seus impactos socioambientais.

A matriz de transição, através da diferença entre as áreas das classes de 1999 e 2018, mostra as áreas que foram conservadas e transformadas em outras categorias. Os valores 
assinalados na diagonal, nas Tabelas 04 e 05, correspondem às áreas das classes que não sofreram alteração nas respectivas metodologias de classificação.

É possível observar que houve uma perda significativa das áreas de floresta, com uma diminuição de 33\% na classificação GEOBIA e 29\% no classificador Random Forest. Em contrapartida, áreas antrópicas nomeadas como "não floresta" obtiveram um aumento de 48\% na classificação GEOBIA e 55\% no classificador Random Forest.

Tais resultados refletem o aumento de áreas de pastagens, cultivos agrícolas e urbanização constadas (Figura 06). O aumento dessas áreas está relacionado à tendência de expansão de atividades antrópicas impulsionadas pela abertura de estradas e vicinais, como a PA 375 e 136, assim como pela ocupação no entorno de rios.

Observa-se que a bacia se encontra, em 2018, com a maior parte de sua alteração nas cabeceiras, sendo a rede de drenagem diretamente afluente a mesma a mais impactada. O leito principal apresenta o melhor grau de conservação, porém com forte pressão de entorno. A gradação de 1999 para 2018 indica que a concentração das formas de alteração de uso da terra está se aproximando das áreas mais conservadas da bacia, cujo impacto deverá ser em considerado em diversos níveis, desde a produção de sedimentos que poderão migrar em direção aos cursos d'água, soterramento de nascentes e até as modificações estruturais nas áreas de manguezais.

A expansão de atividades antrópicas no nordeste paraense se desenvolveu mais intensamente com a consolidação da estrada de ferro Belém-Brasília, conhecida como BR010 (VALE et al., 2018). Favorecendo o surgimento de cidades e uma rede de estradas, em que a ocupação do território foi orientada mais para o interior, acompanhada com a intensificação de atividades agropecuárias e, consequentemente, o desmatamento (COELHO et al., 2018). Dessa forma, as transformações na paisagem ocorreram devido à intensificação e mudanças nas atividades econômicas na região, como o desenvolvimento da agricultura tradicional e agropecuária.

Esse processo de ocupação na bacia também foi constatado por Teles e Pimentel (2015), reconhecendo que a presença de áreas antrópicas agropecuárias é atualmente responsável pela retirada expressiva da cobertura vegetal na área de estudo, evidenciando a importância dessas atividades para a população local. A ocupação desordenada ocasiona a diminuição de florestas nativas. Situação constatada em visita de campo e evidenciada por Teles e Pimentel (2015), pela presença de grandes áreas em regeneração (Figura 06 g-j). 
|Análise do uso e cobertura da terra na bacia hidrográfica do rio Mocajuba-PA|

|Juliane da Costa Cavalcante | Aline Maria Meiguins de Lima |

Figura 06 - (a) (b) Áreas de não floresta (pastagem). (c) (d) Áreas de não floresta (agricultura). (e) (f) Áreas de não floresta (urbanização). (g) (h) (i) (j) Formação florestal.
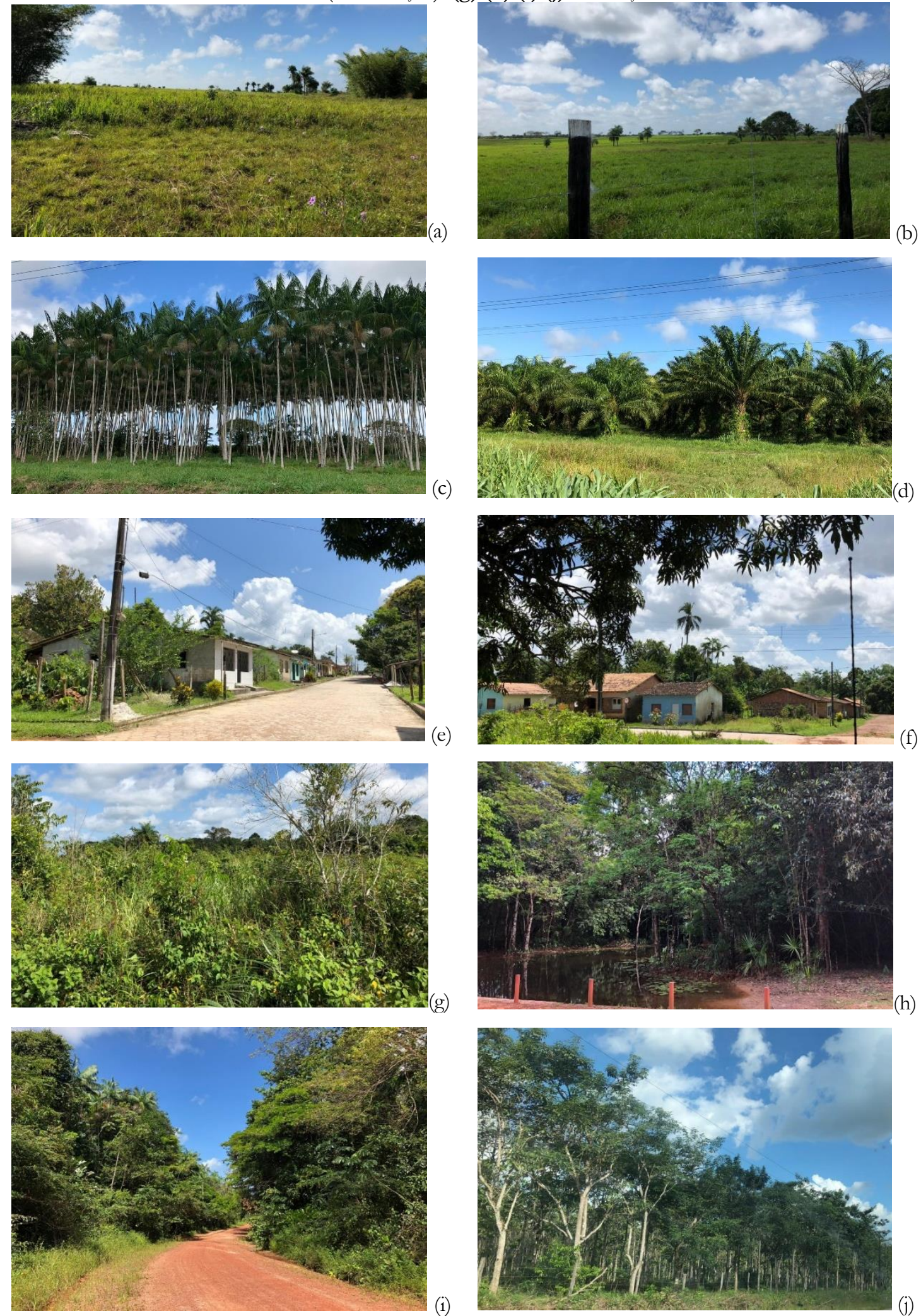

Organização: Autoras.

A extensa área de vegetação secundária é resultado do modelo de produção derruba-queima e posterior abandono da área com o objetivo de recuperar a fertilidade do 
|Análise do uso e cobertura da terra na bacia hidrográfica do rio Mocajuba-PA|

|Juliane da Costa Cavalcante | Aline Maria Meiguins de Lima |

solo (COELHO et al., 2018). Como consequência da redução de florestas se tem o aumento da fragmentação dos habitats naturais, acarretando a perda de espécies de fauna e flora.

A fragmentação da paisagem é um processo intrínseco a expansão de atividades antrópicas. De acordo com Costa et al. (2015), quanto maior a fragmentação de uma paisagem, maior será a influência de fatores externos nos fragmentos. Ou seja, maior a sensibilidade e fragilidade desses ambientes naturais. Coelho et al. (2018) consideram que os distúrbios causados pela conversão de florestas são resultantes do processo de fragmentação florestal, sendo uma ameaça ao funcionamento das comunidades bióticas e contribuindo para o empobrecimento da biodiversidade.

O crescimento de ocupações antrópicas na bacia do Rio Mocajuba ocasiona a pressão em Áreas de Preservação Permanente (APP’s). O Código Florestal (Lei 12.651/2012) considera margens de cursos d'água naturais e manguezais como APP's. Dessa forma, para os cursos d’água há uma largura mínima de vegetação a ser preservada de acordo com a largura do corpo hídrico e para os manguezais deve haver a preservação de toda sua extensão.

Entretanto, a proteção dessas áreas não ocorre em várias extensões da bacia. Margens de cursos d'água que encontram-se sem proteção da vegetação ciliar (Figura 07a,b) são de fundamental importância para o controle destes ambientes, como forma de conter a erosão, assim como melhorar a quantidade e qualidade das águas (VIEGAS et al., 2018).

Nessa mesma situação se encontram as áreas de manguezal que são protegidas legalmente por três Reservas Extrativistas Marinhas (RESEX) que foram criadas com o objetivo de proteger os mangues contra a expansão de atividades antrópicas. As RESEX que possuem áreas que fazem parte da bacia são: RESEX Mãe Grande Curuçá e São João da Ponta criadas em 2002, e RESEX Mocapajuba criada em 2014.

Observou-se que determinados seguimentos de manguezal eram englobados por vegetação em regeneração (Figura 07e,f), evidenciando a supressão de áreas de mangue. Essas áreas de vegetação secundária foram observadas por Vale et al. (2018) na RESEX Mocapajuba entre os terrenos marinhos e de terra firme, resultados do processo de ocupação das comunidades, abertura de áreas para cultivos agrícolas de subsistência e pastagens.

Menezes et al. (2008) afirmam que a regeneração de manguezais ocorre de maneira distinta da floresta original, como é o caso do estudo realizado por Berger et al. (2006) abordando a recuperação de manguezais em campos de arroz abandonados onde a 
diminuição na disponibilidade de nutrientes pode ser responsável por mudanças relativas nas taxas de crescimento de diferentes espécies.

A vasta extensão de áreas de vegetação em processo inicial, intermediário e avançado de regeneração, que fazem parte da classe "formação florestal", possuem função essencial na reestruturação da fauna e flora locais. De acordo com Coelho et al. (2018), as florestas secundárias podem ter papel importante na conservação biológica e no processo de recuperação ambiental, quando mantida em paisagens antropizadas.

Adjacente a essas áreas de manguezal impactadas se encontram áreas antropizadas e impermeabilizadas (Figura 07g,h). De acordo com Lacerda et al. (2006) e Godoy (2015) mudanças no uso da terra possuem a capacidade de alterar a carga e granulometria de sedimentos que chegam aos manguezais, visto que a expansão e permanência desses ecossistemas dependem do equilíbrio entre erosão e sedimentos de uma dada região costeira. Dessa forma os manguezais respondem não somente aos impactos locais, mas também às perturbações que ocorrem ao longo de toda sua bacia hidrográfica, interferindo na sua resiliência natural.

O ecossistema manguezal necessita de condições específicas para se manter, como teor de salinidade adequado, penetração da água do mar, solo composto de silte e argila fina, matéria orgânica, além da livre circulação das águas, pois grande parte do material orgânico (nutrientes) produzido pelas árvores é trazido pelas águas marinhas e continentais. No entanto, alterações antrópicas podem interferir nas características desse ambiente, como é o caso da PA-458 que aterrou $25 \mathrm{~km}$ de Manguezal entre o município de Bragança e a praia de Ajuruteua. A obra foi concluía em 1991 e hoje a área de manguezal suprimida se encontra em processo lento de recuperação, com características bem diferentes do ecossistema original (OLIVEIRA; HENRIQUE, 2018).

Áreas de manguezal preservadas se encontram em locais mais isolados, como ilhas, e distantes de interferências antrópicas (Figura 07i,k). Nas áreas de manguezal e no entorno do rio principal são exercidas atividades econômicas locais como pesca, coleta de caranguejo e criação de ostras. Sendo que 26 comunidades são usuárias dos recursos naturais da bacia por meio dessas atividades tradicionais de baixo impacto ambiental. Além de que a criação das RESEX São João da Ponta e Mãe Grande Curuçá têm conduzido a população local a ter mais cuidado com a proteção dos recursos naturais por meio da regularização e manejo desses recursos. Por outro lado, o entorno das RESEX sofre a falta de um plano de ação para conter atividades predatórias (TELES; PIMENTEL, 2018). 
|Análise do uso e cobertura da terra na bacia hidrográfica do rio Mocajuba-PA|

|Juliane da Costa Cavalcante | Aline Maria Meiguins de Lima |

Figura 07 - (a) (b) (c) (d) Áreas de Preservação Permanente. (e) (f) Áreas de manguezal alteradas. (g) (h) Áreas antropizadas adjacente aos manguezais. (i) (j) (k) Manguezais afastadas de interferências antrópicas.
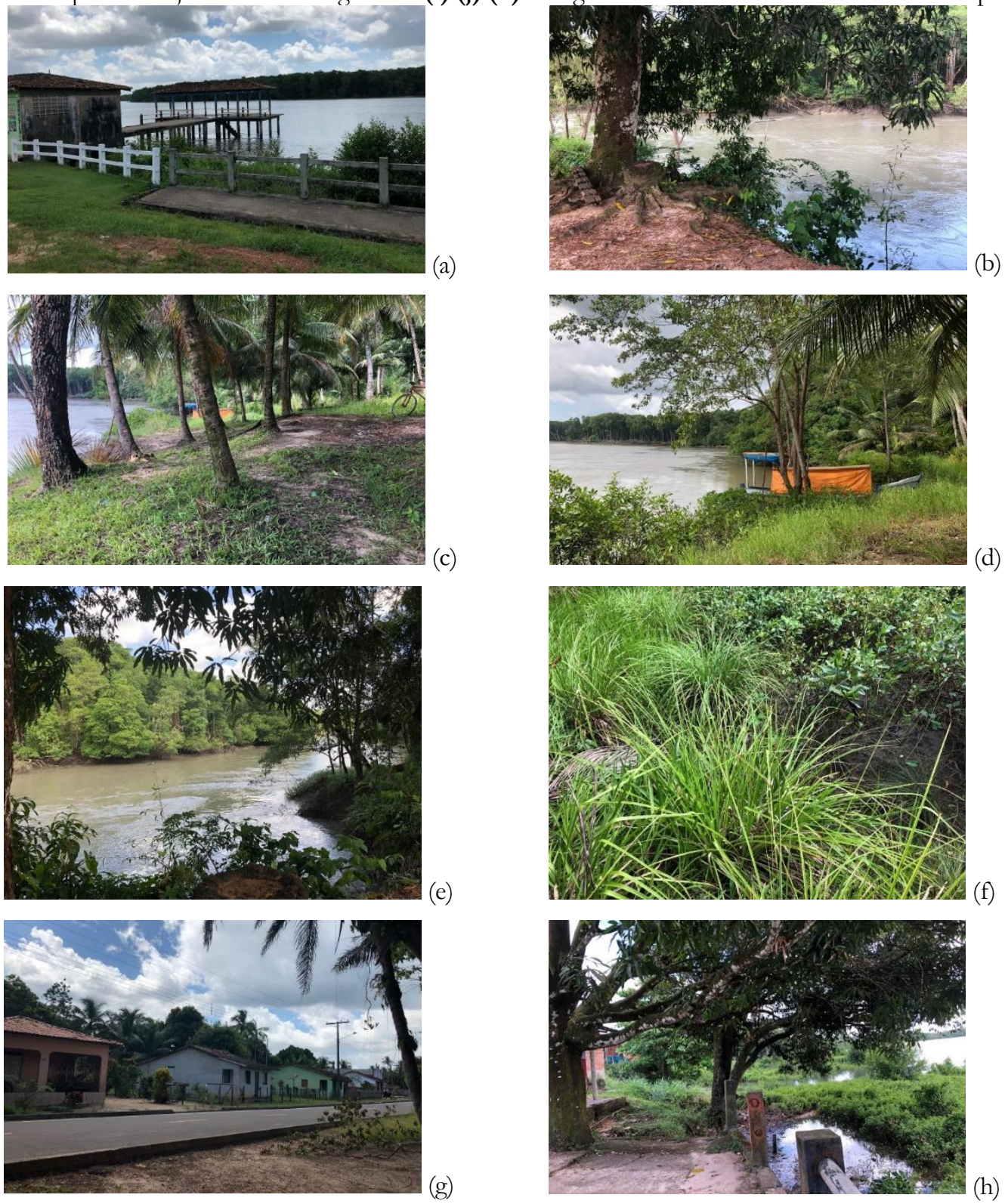

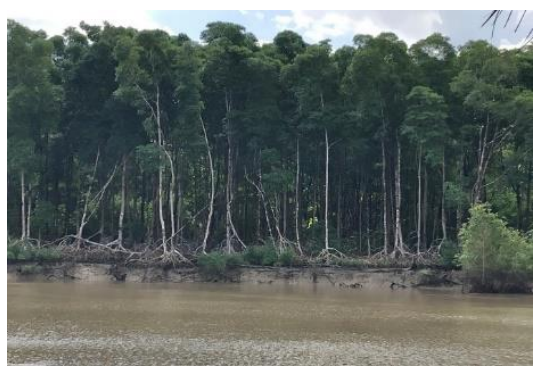

(i)

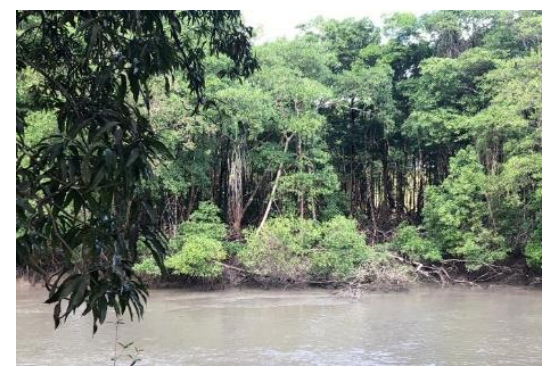

(j)

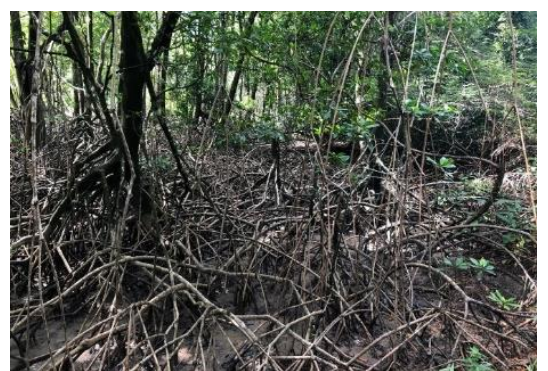

$(\mathrm{k})$

Esse fato destaca a importância das zonas de preservação do nordeste paraense, onde as RESEX foram criadas para proteger os ecossistemas de manguezal, prevenindo e mitigando a degradação do ambiente e a perda de biodiversidade. Ecossistemas esses que abrigam no seu entorno populações locais que usam dos recursos naturais para sua 
subsistência e atuam como agentes fiscalizadores na proteção das Unidades de Conservação. No entanto, como entraves se têm a falta de políticas públicas incentivando a conservação, educação ambiental e inclusão das comunidades tradicionais na gestão das unidades, e um plano de ações como tomada de decisão para as demandas das reservas, assim como a finalização dos planos de manejo das RESEX's que se encontram em construção.

De acordo com Teles e Pimentel (2018), devido a interesses divergentes do poder público local não há ações para o entorno das unidades de conservação, pois demandam investimentos financeiros e uma articulação mais efetiva com o poder do governo local. Nesse caso ressalta-se a ausência de uma secretaria de meio ambiente no município de São João da Ponta como agente de controle e fiscalização de atividades predatórias.

Ao observar os mapas de uso da terra da bacia hidrográfica do Rio Mocajuba é possível atentar que foi uma região que sofreu um intenso processo de desmatamento. $\mathrm{O}$ desenvolvimento de atividades econômicas ocasionou o incremento de atividades antrópicas na bacia, resultando em impactos negativos no meio físico, como fragmentação e descaracterização dos ecossistemas. Onde áreas de grande importância para a preservação da biodiversidade local, como áreas de APP's e manguezais, foram suprimidas por ocupações antrópicas.

O comprometimento dos recursos hídricos também pode ser destacado, uma vez que as áreas prioritárias para produção de água (nascentes) podem ser suprimidas pela alteração das formas de cobertura da terra, além da geração de sedimentos por perdas ocasionadas pela erosão, que altera a geometria das margens dos canais e as condições de escoamento superficial das águas.

Mesmo com a criação das RESEX para a proteção dos manguezais e populações tradicionais observou-se áreas de mangue ameaças por ocupações antrópicas, como urbanização e agricultura. Isso acaba por evidenciar alguns entraves para a efetivação dessas Unidades de Conservação, como uma fiscalização ineficiente devido a extensas áreas de APP's e manguezais ocupadas ilegalmente, a falta de recursos e de corpo técnico, dificuldades de comunicação e divergências entre os governos locais, ausência de engajamento e inclusão da população local para ações de conservação e conscientização, além da falta de um plano de manejo e políticas públicas voltadas para a região.

\section{CONCLUSÃO}


Entender as alterações da paisagem ocasionadas pelas expansões das ocupações antrópicas, por meio da geração de mapas de uso e cobertura da terra, são fundamentais para o conhecimento dos processos socioambientais dentro de um sistema, que são modificados pelas alterações nas relações econômicas e transformações nos usos da terra. Simultaneamente a esses processos acontecem as modificações no ambiente natural que acabam por colocar em risco a permanência da biodiversidade, interferindo negativamente no fornecimento de bens e serviços ecossistêmicos às comunidades locais.

Dessa forma, o estudo da evolução da ocupação na bacia do Rio Mocajuba serviu para analisar a expansão das áreas de uso antrópico no intervalo de 20 anos. Confirmando o fato que o aumento das atividades antrópicas na bacia pressiona as áreas de mangue das RESEX, devido à falta de políticas públicas e um plano de ações para conter essas atividades no entorno das UC's. Da mesma forma, a falta de um agente de controle e fiscalização das APP's colocam em risco a integridade dos recursos hídricos da bacia.

Portanto, para que os ecossistemas naturais sejam desfrutados de uma forma sustentável deve-se planejar e administrar as áreas antrópicas e as áreas que devem ser preservadas de uma forma conjunta, visto que a proteção apenas dos manguezais não é suficiente se o entorno estiver comprometido. Já que a fragilidade e resiliência desses ambientes podem estar comprometidas.

Em outra perspectiva, as metodologias utilizadas na elaboração dos mapas de uso da terra, apesar dos resultados distintos, obtiveram acurácia consideradas favoráveis para estudos de uso e cobertura da terra e expansão de áreas antropizadas. Confirmando que as distintas metodologias podem ser incrementadas com índices espectrais, aumentando a acurácia da classificação e enriquecendo os métodos.

\section{AGRADECIMENTOS}

Coordenação de Aperfeiçoamento de Pessoal de Nível Superior (CAPES) e ao Conselho Nacional de Desenvolvimento Científico e Tecnológico (CNPq) pelos recursos destinados à pesquisa. Ao Laboratório de Análises de Imagens do Trópico Úmido (LAIT) e ao Laboratório de Estudos e Modelagem Hidroambientais (LEMHA) da Universidade Federal do Pará (UFPA), pelo suporte oferecido.

\section{REFERENNCIAS}

BARBOSA, A. H., CARVALHO, R.; CAMACHO, R. Aplicação do NDVI para a Análise da Distribuição Espacial da Cobertura Vegetal na Região Serrana de Martins e Portalegre estado do Rio Grande do Norte. Revista do Departamento de Geografia, v. 33, 128 - 


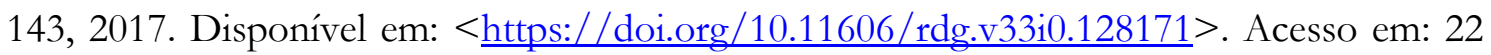
abr. 2019.

BERGER, U.; ADAMS, M.; GRIMM, V.; HILDENBRANDT, H. Modelling secondary succession of neotropical mangroves: causes and consequences of growth reduction in pioneer species. Trends in Plant Science and Evolution, v. 7, n. 4, p. 243-252, 2006. Disponível em: < https://doi.org/10.1016/j.ppees.2005.08.001>. Acesso em: 15 abr. 2019.

BRASIL. Ministério do Meio Ambiente - MMA. Shapefile Unidades de Conservação. 2019. Disponível em: < https://www.mma.gov.br/areas-protegidas/cadastro-nacional-deucs/>. Acesso em: 22 ago. 2019.

COELHO, A. S. P. M. [et al.]. Impactos das mudanças de uso da terra nas áreas prioritárias para conservação da biodiversidade no nordeste do estado do Pará, Brasil. Boletim do Museu Paraense Emílio Goeldi. Ciências Naturais, v. 13, n. 1, p. 107-120, 2018. Disponível em: $\quad \underline{\text { http://editora.museu- }}$ goeldi.br/bn/artigos/cnv13n1 2018/impactos(coelho).pdf>. Acesso em: 16 abr. 2019.

COSTA, O. B.; MATRICARDI, E. A. T.; PIRES, J. S. R. Análise do Processo de Fragmentação da Floresta nos Municípios de Corumbiara e Buritis - RO. Floresta e Ambiente, v. 22, n. 3, p. 334-344, 2015. Disponível em: < http://dx.doi.org/10.1590/2179-8087.044113 >. Acesso em: 16 abr. 2019.

DINIZ, C. [et al.]. Brazilian Mangrove Status: three decades of Satellite Data Analysis. Remote Sensing, v. 11, n. 7, p. 808-826, abr. 2019. Disponível em: < https://doi.org/10.3390/rs11070808>. Acesso em: 10 dez. 2019.

FERNANDES, R. R.; NUNES, G. M.; SILVA, T. S. F. Classificação orientada a objetos aplicada na caracterização da cobertura da terra no Araguaia. Pesquisa Agropecuária Brasileira, v. 47, n. 9, p. 1251-1260, 2012. Disponível em: < http://dx.doi.org/10.1590/s0100-204x2012000900010>. Acesso em: 17 abr. 2019.

GEE. Google Earth Engine. 2019. Disponível em: < https://code.earthengine.google.com/>. Acesso em: 03 fev. 2019.

GISLASON, P. O.; BENEDIKTSSON, J. A.; SVEINSSON, Johannes R. Random Forests for land cover classification. Pattern Recognition Letters 27(4): 294-300, 2006. Disponível em:<http://dx.doi.org/10.1016/j.patrec.2005.08.011>. Acesso em: 03 mar. 2019.

GODOY, M. D. P. Alteração nas Áreas de Mangue em Estuários no Estado do Ceará devido a Mudanças nos Usos do Solo e Mudanças Climáticas. 2015. 202 f. Tese (Doutorado) - Curso de Ciências Marinhas Tropicais, Instituto de Ciências do Mar, Universidade Federal do Ceará, Fortaleza, 2015.

GORELICK, N.; HANCHER, M.; DIXON, M.; ILYUSHCHENKO, S; THAU, D. \& MOORE, R. 2017. Google Earth Engine: Planetary-scale geospatial analysis for everyone. Remote Sensing of Environment, 202:18-27. Disponível em:<https://doi.org/10.1016/j.rse.2017.06.031>. Acesso em: 05 mar. 2019. 
IBGE. Manual técnico da vegetação brasileira: sistema fitogeográfico, inventário das formações florestais e campestres, técnicas e manejo de coleções botânicas, procedimentos para mapeamentos. Rio de Janeiro: IBGE, 2012. 271 p.

JENSEN, J. R. Introductory digital image processing: a remote sensing perspective. 2. ed. Upper Saddle River: Prentice Hall, 1996. 316 p.

KWANG, C.; JNR, E. M. O.; AMOAH, A. S. Comparing of Landsat 8 and Sentinel 2A using Water Extraction Indexes over Volta River. Journal of Geography and Geology, v. 10, n. 1, p. 1-7, 2017. Disponível em: < http://dx.doi.org/10.5539/igg.v10n1p1>. Acesso em: 08 mar. 2019.

LACERDA, L. D. [et al.]. Manguezais do Nordeste e mudanças ambientais. Ciência Hoje, Rio de Janeiro, p. 24-29, 2006. Disponível em: $<$ https://www.researchgate.net/publication/271519241 Manguezais do Nordeste $>$. Acesso em: 10 mar. 2019.

MENEZES, M. P. M.; BERGER, U.; MEHLIG, U. Mangrove vegetation in Amazonia: a review of studies from the coast of Pará and Maranhão states, North Brazil. Acta Amazônica, v. 38, n. 3, p. 403-420, 2008. Disponível em: $<$ http://www.scielo.br/scielo.php?script=sci arttext\&pid=S0044-59672008000300004 > .

Acesso em: 14 mar. 2019.

OLIVEIRA, M. V. C.; HENRIQUE, M.C. No meio do caminho havia um mangue: impactos socioambientais da estrada Bragança-Ajuruteua, Pará. História, Ciências, Saúde-Manguinhos, v. 25, n. 2, p. 497-514, 2018. Disponível em: < http://dx.doi.org/10.1590/s0104-59702018000200011>. Acesso em: 16 mar. 2019.

PAZ, J. P. S.; VIEIRA, C. V. Evolução do uso e cobertura do solo no município de São Francisco do Sul - estado de Santa Catarina. Boletim Paranaense de Geociências, v. 74, n. 1, p. 28-36, 2018. Disponível em: <http://dx.doi.org/10.5380/geo.v74i1.50945>. Acesso em: 20 mar. 2019.

PEREIRA, G. H. A.; LOHMANN, M.; MAGANHOTTO, R. F. Proposta e avaliação de índices para delimitar e mapear corpos d'água utilizando imagens do satélite LANDSAT 8. Revista Brasileira de Geografia Física, v. 6, n. 9, p. 1956-1968, nov. 2016. Disponível em: < https://periodicos.ufpe.br/revistas/rbgfe/article/view/233731>. Acesso em: 20 mar. 2019.

PIAZZA, G. A.; VIBRANS, A. C. Classificação orientada a objetos para mapear florestas secundárias em Santa Catarina, sul do Brasil. Revista Brasileira de Cartografia, v. 66, n. 5, p. 993-1005, 2014. Disponível em: $<$ https://www.researchgate.net/publication/275582909 Classificacao orientada a objeto s para mapear florestas secundarias em Santa Catarina sul do Brasil>. Acesso em: 20 mar. 2019.

ROSA, M. R. Classificação do padrão de ocupação urbana de são paulo utilizando Aprendizagem de Máquina e Sentinel 2. Revista do Departamento de Geografia, v. esp., p. 15-21, 2018. Disponível em: < https://doi.org/10.11606/rdg.v0ispe.145784>. Acesso em: 23 mar. 2019. 
SAMPAIO, A. C. F. [et al.]. Classificação ambiental dos fragmentos florestais da área rural do município de Maringá-PR, Brasil: primeiras etapas. Revista em Agronegócio e Meio Ambiente, v. 11, n. 1, p. 253-276, 2018. Disponível em: < http://dx.doi.org/10.17765/2176-9168.2018v11n1p253-276>. Acesso em: 20 mar. 2019.

SILVA, L. C. N.; BACANI, V. M. Classificação orientada a objeto (GEOBIA) aplicada à análise das alterações do uso e cobertura da terra da Bacia Hidrográfica do Rio da Prata em Jardim e Bonito - MS. Geografia, v. 26, n. 1, p. 05-18, 2017. Disponível em:

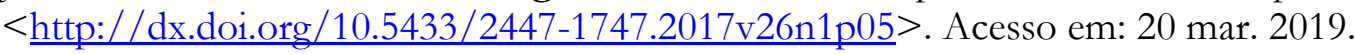

SILVA, L. F.; BACANI, V. M. Análise da fragilidade ambiental e das Áreas de Preservação Permanente da bacia hidrográfica do Córrego Fundo, município de Aquidauana-MS. Caderno de Geografia, v. 27, n. 49, p. 264-284, 2017. Disponível em: < https://doi.org/10.5752/P.2318-2962.2017v27n49p264>. Acesso em: 20 mar. 2019.

SOUSA, D. G.; MINCATO, R. L.; KAWAKUBO, F. S. Análise multitemporal do uso da terra utilizando imagens Landsat-5 da região de Alfenas, Sul de Minas Gerais, visando a conservação de fragmentos florestais. Revista Brasileira de Geografia Física, v. 8, n. 5, p. 1482-1492, 2015. Disponível em: $<$ https://periodicos.ufpe.br/revistas/rbgfe/article/view/233269>. Acesso em: 25 mar. 2019.

SPINELLI, M. V. P.; CARVALHO, R. M. C. M. O.; SILVA, H. P.; BRANDÃO, S. S. F.; FRUTUOSO, M. N. M. A. Estudo sustentável da capacidade de carga antrópica e a sua influência no ponto de equilíbrio da resiliência ambiental. Revista Brasileira de Geografia Física, v. 9, n. 1, p. 185-199, 2016. Disponível em:

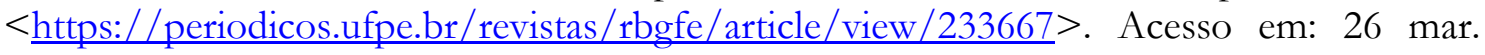
2019.

TEIXEIRA, G. M. [et al.]. Análise de classificadores de estágios sucessionais em um fragmento de Mata Atlântica. Biofix Scientific Journal, v. 2, n. 4, p. 88-96, 2019. Disponível em: < http://dx.doi.org/10.5380/biofix.v4i2.64233> . Acesso em: 27 mar. 2019.

TELES, G. C.; PIMENTEL, M. A. S. A nova perspectiva de Geossistema, proposta por Bertrand, aplicada a bacia hidrográfica do rio Mocajuba - Nordeste Paraense. Boletim Campineiro de Geografia, v. 5, n. 2, p. 381-389, 2015. Disponível em: $<$ http://agbcampinas.com.br/bcg/index.php/boletim-campineiro/article/view/239>. Acesso em: 27 mar. 2019.

TELES, G. C.; PIMENTEL, M. A. S. Análise de conflitos socioambientais nas Reservas Extrativistas de São João da Ponta e Curuçá - PA. Geoambiente, v. 31, p. 193-2011, 2018. Disponível em: < https://doi.org/10.5216/revgeoamb.v0i31.48852>. Acesso em: 30 mar. 2019.

USGS. United States Geological Survey. Earth Explorer. 2018. Disponível em: $<$ https://earthexplorer.usgs.gov/>. Acesso em: 05 jul. 2018.

VALE, J. R. B.; COSTA, J. A.; SANTOS, J. F.; SILVA, E. L. S. Análise comparativa de métodos de classificação supervisionada aplicada ao mapeamento da cobertura do solo no município de Medicilândia, Pará. InterEspaço: Revista de Geografia e Interdisciplinaridade, Grajaú-MA, v. 4, n. 13, p. 26-44, jan./abr. 2018. Disponível em: < http://dx.doi.org/10.18764/2446-6549.v4n13p26-44>. Acesso em: 05 abr. 2019. 
|Juliane da Costa Cavalcante | Aline Maria Meiguins de Lima |

VALE, J. R. B.; LEITE, T. V. S.; SILVA, E. L. S.; SANTOS, J. F. Análise espacial das unidades de paisagem da reserva extrativista Marinha Mocajuba, Zona Costeira do Nordeste Paraense. Revista Cerrados, v. 16, n. 2, p. 153-173, 2018. Disponível em: < http://dx.doi.org/10.22238/rc24482 6922018 1602153173>. Acesso em: 27 abr. 2019.

VALLE, I. C.; FRANCELINO, M. R.; PINHEIRO, H. S. K. Mapeamento da Fragilidade Ambiental na Bacia do Rio Aldeia Velha, RJ. Floresta e Ambiente, v. 23, n. 2, p. 295-308, 2016. Disponível em: <http://dx.doi.org/10.1590/2179-8087.107714>. Acesso em: 31 ago. 2019.

VIEGAS, S; ALMEIDA, R. M.; SOUZA, F. S. A identificação das áreas de preservação permanente no município de Santarém, estado do Pará, Brasil, a partir de técnicas de geoprocessamento. Revista Geonorte, v. 9, n. 33, p. 153-169, 18 dez. 2018. Disponível em: <http://dx.doi.org/10.21170/geonorte.2018.v.9.n.33.153.169>. Acesso em: 15 abr. 2019. 